\title{
The Application of Business Process Management in the Hospitality Industry: A Case Study
}

\section{Stepan CHALUPA and Martin PETRICEK}

The Institute of Hospitality Management in Prague, Prague, Czech Republic

Correspondence should be addressed to: Stepan CHALUPA; chalupa@vsh.cz

Received date:29 January 2020; Accepted date: 28 May 2020; Published date: 23 July 2020

Academic Editor: Katarina Tomičić-Pupek

Copyright (C) 2020. Stepan CHALUPA and Martin PETRICEK.Distributed under Creative Commons Attribution 4.0 International CC-BY 4.0

\begin{abstract}
The study focuses on the application of Business Process Management and modelling within the hospitality industry. The lack of recent research shows the need for a deeper understanding of this topic and its application in the hospitality industry. This paper focuses on the use of BPM in a four-star hotel located in city-centre of Prague. An overview model was created to distinguish the core, managerial and supporting processes. Within the core processes, accommodation services were selected for a more in-depth description. The check-in sub-process was modelled on the level of EPC (Event-Drive Process Chain) where thanks to observation; the processing times were measured to provide a platform for further optimisation. Critical shortcomings were identified within the activities that do not involve interaction with the client. Thanks to the application of the available technologies; an increase in the processing times was reached, as well as the increase in the incremental revenue generation. Due to the higher involvement of clients and time saving within other activities, front-desk employees were able to increase the overall satisfaction level of hotels' guests which stimulated the hotel online reputation (increase in online hotel perception).
\end{abstract}

Keywords: Business process modelling, front-office process model, check-in optimisation

Cite this Article as: Stepan CHALUPA and Martin PETRICEK (2020)," The Application of Business Process Management in the Hospitality Industry: A Case Study", IBIMA Business Review, Vol. 2020 (2020), Article ID 301930, DOI: 10.5171/2020.301930 


\section{Introduction}

The intensive application of new technologies in the hospitality industry is shifting the way how hotels and other accommodation facilities are being operated. This shift is connected with the need for understanding hotel processes and their evaluation or optimisation. Errors in hotel operations can lead to a decrease in client satisfaction, and due to internationalisation and globalisation, high levels of competition and increasing client's needs, these errors can be fatal for the hotel. The application of new approaches, innovations and data usage are the way to maintain a high level of service and competitive advantages. One way is the business process management, which is intensively used in other industries.

Business Process Management (BPM) can be perceived as a set of methods, techniques and tools used for identifying, analysing, optimising (redesigning) and monitoring processes with a focus on productivity increase and cost reduction (Dumas et al., 2013). The main focus of this managerial approach is on Business Processes (BP), sets of coordinated activities prosecuted by people (users) in order to achieve smart objectives and company goals (Doebeli et al., 2011) and their notation, process modelling, (PM).

The business PM is providing support to organisational processes using software tools to control and analyse business activities while including people, organisations, documents, technical equipment and other assets, IT applications and other related information (Tan et al., 2013). PM is also supporting the business goals in three main areas: process description in order to deeply understand the activities and interactions of people and technologies (Curtis, Kellner \& Over, 1992); process analysis, using qualitative or quantitative approaches (Reijers \& Mendling, 2011) and process simulation (Mili et al., 2010). Using PM, organisations can not only increase the productivity and reduce costs but also improve the communication channels and reduce communication inconsistencies (Becker, Rosemann \& Van Uthmann, 2000; Hammer, 2010).

A crucial part of BPM is its comprehensive understanding by stakeholders (Stein Dani, Dal Sasso Freitas \& Thom, 2019). Several studies show the negative impact of lacking BPM knowledge in stakeholders and modellers (Geiger et al., 2018; Doldeberg Júnior et al., 2018).

This paper focuses on the use of BPM and PM in the hospitality industry, directly in hotel operations. Services are always connected to a high level of interpersonal communication and interactions where the standardisation is being applied to deliver an expected level of services to the client. Several hotels are having SOPs (Standardized Operational Procedures) that are used to describe the workflow of the activities needed to be prosecuted for processing quests inquiries. The application of BPM can bring a better, deeper and more comprehensive understanding of these processes and identify problematic areas or inefficiencies in the hotel operation.

\section{Literature Review}

The application of business PM in hospitality is weakly examined by researchers and only a few studies, focusing on this topic, can be found. Krstic, Kahrovic \& Stanisic (2015) are proposing a framework for the application of BPM in the hospitality industry. The main focus of their study is on a holistic approach towards processes and their execution. Using examples of hotel services 
processes, the authors are presenting the possibilities of using BPM, while creating a general methodological framework. The proposed framework is lately used within the study of Xuhuaet al. (2018) for identifying new innovative strategies for a small hotel in Ghana.

Han, Lustigova \& Chalupa (2016) are focusing on the resort gastronomy stand model creation. The created model is based on observed data with an emphasis on the revenue generation and customer needs fulfilment. The "as-in" model was used to identify operation errors in staff movement and later precreated to a new operation model, keeping the service structure with an emphasis on queue management and revenue optimisation. The real observed data were used to simulate the behaviour of the system after redesigning the process. The output of this study shows the feasibility of BPM use in gastronomy. In the study of Poulova et al. (2019), a hotel process simulator was proposed to allow hotel managers and university students to solve the operational "what-if" questions.

Nebel, Rutherford \& Schaffer (1994) proposed a process reengineering as a way to increase the efficiency of the operation. During the process of reengineering, the reengineering team should evaluate the process maps of core activities and later propose a process-oriented functional map abstracting from commonly used organisational structures. Thanks to the process reengineering, the hotel manager can effectively measure the performance using customer-based criteria, a plan preparation and complex preparation shifts, and improve the interpersonal communication within the organisation. The same approach toward operations innovations is proposed by Sinclair \& Sinclair (2009).

A seamless customer experience, based on the process redesign and the organisation shift from a formal organisational structure to a process lead organisation, is being described as well by Chacko (1998) or Chacko, Williams \& Schaffer (2012). Akin Aksu (2001) proposes a process redesign and the use of new technologies with a focus on Total Quality Management. The focus on quality management is also proposed by Ingram (1997). Kozak \& Gürel (2015) are focusing on process standardisation and quality management. As the business process management is closely connected to quality management, process modelling and optimisation play a crucial role in human resources management as well (Kim, Tavitiymana \& Kim, 2009).

Özdemir, Colak \& Shmilli (2018) are focusing on the front-desk processes of pre-arrival, arrival, accommodation, stay and departure. The results show not only the need for using the available technologies but also supporting documents and other assets that should minimise the time spent by operating computers and hotel systems. The used system should be able to prepare the needed data for smooth reservation handling and check-in and payment processing. Using the available technologies in process optimisation is proposed by Beldona, Beck \& Qu (2001).

\section{Methodology and Data Collection}

To identify and model business processes within hotel operations, a methodology supported by ARIS Architect was used, including minor customisations to better fit the specifics and needs of the hospitality industry. The methodology of ARIS is being used to standardise the notation of business processes and their possible redesign or optimisation. Modelled processes are created on several levels to assure a global and comprehensive understanding of partial processes and their interconnection. 
This global overview is represented by a meta-model, which consists of an organisation structure, documents and knowledge, processes, E2E scenarios, information and communication technologies, technical equipment, goals, and inputs and outputs (accomplishments). This overview represents not only the processes but all the assets needed for their prosecution as well.

When focusing on processes and their structure, four different levels are used. A general overview is represented by the Overview model, which consists of Control processes, Core processes and Support processes. Core processes are directly connected to delivering a value to the client as well as the direct interactions with him, whereas Support processes are being executed to prepare the needed assets for Core processes without a direct interaction with the client. Control processes are responsible for managerial and control activities that coordinate the whole organisation, usage of assets and goals setting.

These process groups are modelled in details in the Value-added chain diagram, which describes the sub-processes and their interconnection. These subprocesses represent the meaningful division of activities into groups to distinguish the differences in the subprocess structures and usage of assets. The identified sub-processes are connected to the Overview model through Function allocation diagram. This model consists of an identified sub-process, inputs and outputs, used technical equipment including information systems, the owner and other connected roles, an external user of the sub-process, documents needed for sub-processes prosecution and output documents, the main goal of the sub-process, and the identified risks.
To describe partial activities, the Eventdriven process chain model is used. Using EPC, events and activities (functions) are compiled to describe, in details, partial activities that can be measured, and based on the measurements, the decision is made to redesign or optimise.

ARIS methodology can help optimise and standardise hotel operations through an authentic visualisation of the processes and their models. Based on the granularity of models, hoteliers can understand the processes, their interconnection and the possible risks, and narrow spaces properly.

To measure the efficiency of the models created, a timeline for the selected EPC was created and measured using observation. The time needed to prosecute partial activities was measured for individual clients and the nd the individual timelines were created. These single cases were connected to comments to understand the differences between these measurements properly. The selected process (Check-In) was measured 102 times. The model and data are listed below.

All the processes were directly connected to the hotel Louis Leger in Prague. Hotel Louis Leger is located in the broader centre of Prague, Czech republic. Its location within the district of Prague 2 provides its clients with an easy access to Prague city centre and other historical monuments. The hotel has 55 nonsmoking rooms in secession style with a wide range of services in a suitable quality (Booking.com score of 8,7).

The room rates are being set by the senior manager based on the current and forecasted occupancy and they are ranging from 120 - 300 EUR in high seasons to 60 200 in low seasons. The hotel is mainly focusing on leisure clients, where $93 \%$ of the quests are using OTAs or Tour 
Operators, $5 \%$ hotel websites and only 2 $\%$ of the guests are coming directly to the hotel or using a different distribution channel. High rates are, therefore, applied mainly in national (or international) feasts, holidays, summer season and weekends.

Nearly $65 \%$ of the hotel's guests are coming from Italy $(19,5 \%)$, Germany $(17$, $5 \%)$, Czech republic $(11,5 \%)$, United Kingdom (9\%) and Spain (7\%).

\section{Results}

Using the methodology described in the previous section, the core processes of the previously described Prageu hotel were identified and modelled using ARIS Architect tool. Based on the range of services provided by the hotel, three Core process groups were identified (Accommodation Services, F\&B services and Additional services). Figure 1 describes the Value-added chain diagram for Accommodation services where nine sub-processes were identified to capture the customer-oriented chain (main "storyline").

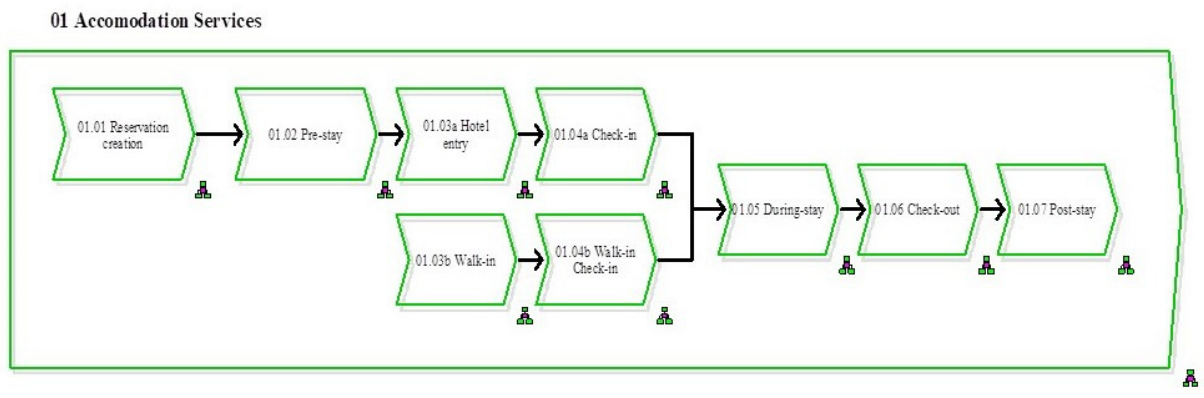

Fig. 1: Value-added chain diagram of Accommodation Services

The whole process is initialised by Reservation creation, followed by Pre-stay sub-process. During the Pre-stay, clients can modify their reservation in terms of dates and number of rooms booked, order more services or, if meeting the terms and conditions of the cancellation policy, cancel the reservation. During this stage, hoteliers can approach the client with marketing activities (Marketing is part of the Support processes). Pre-stay subprocess is only available for clients with created reservation. Walk-ins are handled separately in sub-processes (Walk-in and Walk-in Check-in). The division of these two ways of providing accommodation services is based on the different procedures needed to handle these inquiries. The main focus of this study is on the Check-in sub-process; where clients are being given the stay information and go through a standardised procedure consisting of several activities (EPC diagram of Check-in including the full details can be found in the Appendices).

During-stay consists of handling the requests of the clients during their stays, cross-selling while maintaining a high level of clients' satisfaction and maximising the hotel revenue. Check-out and Post-stay terminate the stay. Post-stay 
is directly connected to the marketing activities of the hotel in the Reputation management and further product distribution.

The Value-added chain diagram does not capture the used assets, only clients-flow within the accommodation service providing process. For a more detailed connection to other models, Function allocation diagram (FAD) was created. Figure 2 represents the FAD of the Checkin process. Focusing on the individual parts of the model, goal, KPI's, inputs and output, used and created documents, internal and external users, used technological assets, and risks were identified.

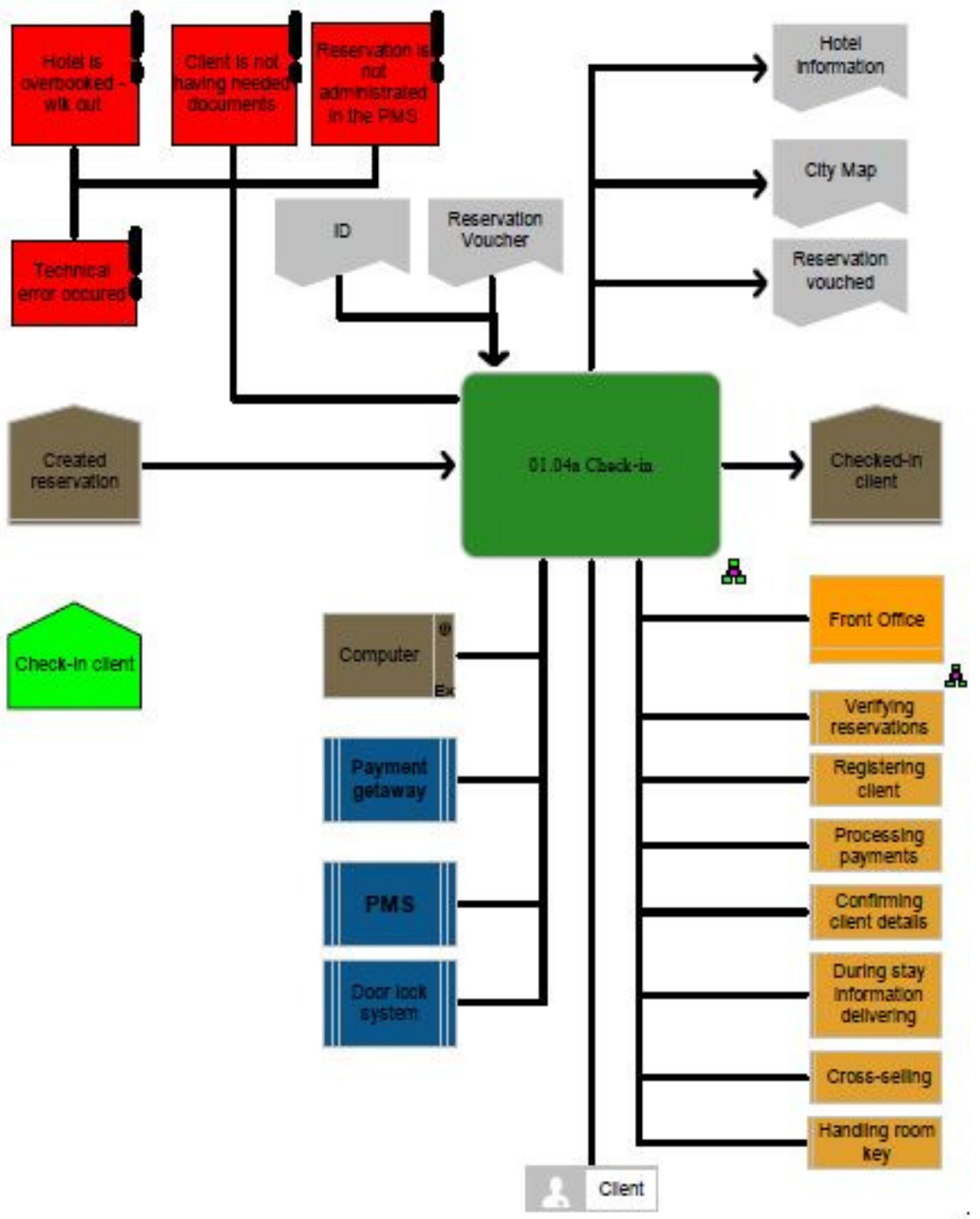

Fig. 2: Function allocation diagram of Check-in sub-process 
The main goal of the sub-process is to successfully check-in the client (occupy a reserved room). The number of successfully accommodated clients is measured by a simple KPI as well as the total number of un-accommodated clients, including reasons for disapproving their requests. The input for the sub-process is created by a Pre-Stay sub-process, the Created reservation, which is being documented by a Reservation voucher. The main output for the During-stay subprocess is the Checked-in client. During the Check-in, several documents are being handled to clients (official Hotel information, City Map and Breakfast voucher - if breakfast is included in the reservation).

Check-in sub-process is having an external user (the Client) and the internal user. The internal user is represented by an organisational group (Front-office department) and set of roles needed to prosecute all the activities of this subprocess. The roles are later-on used for creating job positions and their descriptions to make sure that all the activities are being prosecuted by the employees. This procedure can also be used for job description optimisation. While doing the check-in, PMS, payment getaway and door lock systems are used supported by the computer as a technical tool.

An essential part of FAD is the risk definition. These risks can have a direct impact on the sub-process and can harm the client's satisfaction or the process flow. The risks and their impacts are described below.

- Hotel is overbooked - walk-out. Even though the client arrived at the hotel with a valid reservation voucher, all the rooms are occupied, and the hotel must start the walk-out procedure. Based on the pre-created standards, the client, in this case, is offered an accommodation in a cooperating hotel or the hotel refunds the payment to the client and compensates the difference in another hotel.

- Reservation is not administrated in PMS. This risk consists of several possible events. The client has a third party confirmation, but the reservation fees were not transferred to the hotel. The client is having an invalid reservation voucher (different dates for example). The client has a valid reservation voucher but due to a mistake in the Front-Office, the reservation was not administrated into the PMS. In all these cases, Front-Desk employees should be able to come up with a suitable offer or walk the client out.

- The client is not having the needed documents. During the check-in, the client should give his ID to the Front-Desk staff. According to legislation, a client without a valid ID can not be accommodated. In this case, walkout procedures and a simple disapproval of the request should be done.

- A technical error occurred. During the data processing, confirmation or door lock and payment getaway functionality error, the Front-Desk staff should follow the standardised procedures.

All the previously mentioned risks are markedly influencing the process flow, 
and hotel managers should pay great attention to create standardised procedures to gurantee a high level of personal services.

To benefit from the business process modelling, the times spent in critical activities of the Check-In process were observed on 102 clients. Table 1 describes minimum, mean and maximum times needed to execute the identified main activities in format MM:SS, MS (MINUTES:SECODS, MILISECONDS).

Table 1: Descriptive statistics of the measured time for selected activities

\begin{tabular}{|l|l|l|l|}
\hline Activity & Min & Mean & Max \\
\hline 1. Reservation verification & $0: 04,59$ & $0: 45,56$ & $2: 19,00$ \\
\hline 2. Client registration & $0: 19,00$ & $1: 59,45$ & $7: 02,00$ \\
\hline 3. Personal details confirmation & $0: 16,00$ & $0: 51,04$ & $3: 01,00$ \\
\hline 4. Whole stay information delivery & $0: 11,00$ & $1: 32,05$ & $3: 59,00$ \\
\hline 5. Cross-selling & $0: 00,00$ & $0: 52,21$ & $2: 23,00$ \\
\hline 6. Service payment & $0: 45,00$ & $1: 02,67$ & $1: 53,00$ \\
\hline 7. Key handling & $0: 15,00$ & $0: 49,32$ & $2: 45,00$ \\
\hline
\end{tabular}

The main objective of the study was to optimise the whole process of clients check-in to ensure a high level of services provided to the clients and minimise the time needed to handle partial activities where there is a lack of communication with the client. From this perspective, the identified activities were divided into two groups:

- Activities involving an interaction with the client Reservation verification, Personal details confirmation, Whole stay information delivery, Cross-selling, Service Payment and Key handling.
- Activities not involving an interaction with the client - Client registration.

Time reduction should be mainly applied upon activities that do not involve an interaction with the client; in this view; several proposals were made to increase the efficiency of delivering services on the short and long run. To create more relevant proposals, data about quests' nationalities and employees' language level were collected. Another factor, like the experience of the Front-Desk employees, was not considered, as the team of the hotel was stable last year. During the process of observation, two 
main issues were identified, including a possible solution: Improving the language level of the hotel employees and decreasing the clients' registeration processing time .

In short terms, strengthening the language level is only possible through an intensive language course (currently the in-depth knowledge of German and Italian is slowing down the processing speed) and to comprehensively increase these competencies, the hotel should invest in a long-term learning program. Moreover, as the hotel is not using the full potential of the technologies offered by their PMS provider (including cooperating companies), the hotel manager negotiated testing an ID reader compatible with the PMS.

After the initial training and the testing operations period, the same observation was conducted to measure the impact of the ID reader implementation within the process of Check-In. The results have shown a $13 \%$ decrease in the processing time during the clients registration as well as a $5 \%$ increase in the cross-selling revenue. Not only a direct impact was perceived but the implementation also improved the hotel's average online reputation on Google by 0, 2 mainly in the level of the service provided (the number of positive Front-desk mentions increased).

\section{Discussion}

The presented results of the process optimisation using smart technologies show one of the ways of the business process management use in services. Contrary to other industries, hospitality is directly connected to the communication with clients throughout the different stages of their stay. This contact should be standardised on a property level not influencing the general process of these activities. As presented within the study, processes that are not involving interpersonal interactions with the client could be optimised or redesigned. As proposed by Özdemir, Colak \& Shmilli (2018) and Akin Aksu (2001), processes including clients should be supported by available technologies and assets to reach "nearly seamless" client experience. The focus on a seamless experience can be used to reach more corporate clients, proposing timesaving technologies of digital-born Generation Y (Chacko, Williams \& Schaffer, 2012).

Thanks to the application of the new technology, Front-desk employees were able to focus more on the interaction with clients, cross-selling and sales increase. This orientation should be reflected by the human resources management and revenue management. A proper training should be planned right after hiring the employees (in position training) and further development should be secured.

\section{Conclusion}

To conclude, the field of business process management, business process modelling and optimisation (redesign) in hospitality is not deeply examined and only a few empirical studies can be found. The majority of these studies are not providing empirical data to prove the importance of business process management in hospitality. Due to the high proportion of client-oriented and client involving activities, processes should be designed with the implementation of supporting tools and technologies to provide enough time for communication and cross-selling. This study directly focused on the processes related to the Accommodation services provided in a centrally located four-star hotel in Prague.

The output shows the benefits of further research and BPM application. Due to the various levels of service within the hotel categories, it is crucial to model and compare the complexity of business processes of five and four-star hotels and 
to find the drivers of their efficiency optimisation.

\section{Acknowledgement}

This research was supported by Technology Agency of the Czech Republic within the project TL01000191 "Inovace systémů řízení subjektů cestovního ruchu pomocí nástrojů procesního řízení".

\section{References}

- $\quad$ Akin Aksu, A. (2001), "Re-engineering revisited: a simulation approach", Business Process Management Journal, 7(2), pp. 131-138. https://doi.org/10.1108/146371501 10389704

- Becker, J., Rosemann, M. and Von Uthman, C. (2000). Guideline for business process modelling. Business Process Management. pp. 30-49.

- Beldona, S., Beck, J. and Qu, H. (2001). IMPLEMENTING ENTERPRISE RESOURCE PLANNING IN A HOTEL: TOWARD THEORY BUILDING. International Journal of Hospitality Information Technology, 2(1), pp. 922.

doi: $10.3727 / 153373401803617783$

- Curtis, B., Kellner, M. I. and Over, J. (1992). Process modeling. Communications of the ACM, 35(9), pp. 75-90. doi:10.1145/130994.130998

- Doebeli, G.; Fisher, R.; Gapp, R. and Sanzogni, L. (2011). Using BPM Governance to Align Systems and Practice. Business Process Management Journal,17(2), pp. 184202.

- Dumas, M.; Rosa, M. I.; Mendling, J. and Reijers, H. A.(2013). Fundamentals of Business Process Management. Berlin : Springer, 2013.

- Geiger, M.; Harrer, S.; Lenhard, J. and Wirtz, G.(2018). BPMN 2.0: the state of support and implementation. Future
Generation Computer Systems. 2018, 80, pp. 250-262.

- GoldebergJúnior, V.H.; Dani, V.H.; Avila, D.T.; Thom, L.H.; de Oliveira, J.P.M. and Fantinato., M. (2018). An interface prototype proposal to a samiautomatic process model verification method based on the process modeling guidelines. In:Hammoudi, S.; Śmiałek, M.; Camp, O., \& J. Filipe. ICEIS 2017: Enterprise Information Systems. Berlin : Springer.

- Hammer, M. (2010). What is business process management? In: J. von Brocke a M. Rosemann. Handbook on Business Process Management. Berlin : Springer, 2010, pp. 3-16.

- Han, J., Lustigova, Z. and Chalupa, S. (2016). Resort Gastronomy Stand Simulation. In: SBORNIK MEZINARODNI VEDECKE KONFERENCE: HOTELNICTVI, TURISMUS A VZDELAVANI, proceedings of 8th International Annual Scientific Conference on Hotel Services, Tourism and Education. Praha : VYSOKA SKOLA HOTELOVA \& PRAZE 8, SPOL SRO, SVIDNICKA 506, PRAGUE 8, 181 00, CZECH REPUBLIC, 2016, pp. 38-46.

- Hyun Jeong Kim, Tavitiyaman, P. and Kim, W. G. (2009). The Effect of Management Commitment To Service On Employee Service Behaviors: the Mediating Role of Job Satisfaction. Journal of Hospitality \& Tourism Research, 33(3), 369-390. doi:10.1177/1096348009338530

- Chacko, H. (1998), Designing a seamless hotel organization, International Journal of Contemporary Hospitality Management, 40(4), pp. 133-138. https://doi.org/10.1108/095961198 10222096

- Chacko, H. E., Williams, K. and Schaffer, J. (2012). A Conceptual Framework for Attracting Generation $\mathrm{Y}$ to the Hotel Industry Using a Seamless Hotel Organizational 
Structure. Journal of Human Resources in Hospitality \& Tourism, 11(2), pp. 106-122. doi:10.1080/15332845.2012.648843

- Ingram, H. (1997), Performance management: processes, quality and teamworking, International Journal of Contemporary Hospitality Management, 9(7), pp. 295-303. https://doi.org/10.1108/095961197 10190895

- Kozak, M. A. and Gürel, D. A. (2015).Service design in hotels: A conceptual review. Tourism: An International Interdisciplinary Journal. 63(2), 225-240.

- Krstic, B., Kahrovic, E. and Stanisic, T. (2015). Business process management in hotel industry: A proposed framework for operating processes. Ekonomika. 61(4), pp. 2134.

- Mili, H.; Tremblay, G.; BouJaude, G.; Lefebvre, E.; Elabed, L. and El Boussaidi, G. (2010). Business process modeling languages: Sorting through the alphabet soup. ACM Computing Surveys (CSUR). 43(1), 4-56.

- Nebel, E. C., Rutherford, D. and Schaffer, J. D. (1994). Reengineering the Hotel Organization. Cornell Hotel and Restaurant Administration Quarterly, 35(5), pp. 88-95. doi:10.1177/001088049403500520

- Özdemir, A. İ., Çolak, A. and Shmilli, J. (2018). Business process management in hotels: with a focus on delivering quality guest service. Quality \& Quantity. doi:10.1007/s11135-018-0727-4

- Poulova, P., Cerna, M., Hamtilova, J., Maly, F., Kozel, T., Kriz, P., Han, J. and Ulrych, Z. (2019). Hotel Process Simulator. Proceedings of 12th
International Conference on Blended Learning, ICBL 2019; Hradec Kralove; Czech Republic; 2 July 2019 through 4 July 2019, pp. 128-136.

- $\quad$ Reijers, H. A.and Mendling, J. (2011). A Study Into the Factors That Influence the Understandability of Business Process Models. IEEE Transactions on Systems, Man, and Cybernetics - Part A: Systems and Humans, 41(3), pp. 449-462. doi:10.1109/tsmca.2010.2087017

- Roy, S.; Sajaev, A.S.; Bihary, S. and Ranjan, A. (2014). An Empirical study of error patterns in industrial business process models. IEEE Transactions on Services Computing. 7(2), pp, 140-153.

- Sinclair, M. and Sinclair, C. (2009). Improving Hotel Efficiency Through Integration of Service and Project Management Cultures. International Journal of Hospitality \& Tourism Administration, 10(4), pp. 344-360. doi:10.1080/15256480903337155

- Stein Dani, V., Dal Sasso Freitas, C. M. and Thom, L. H. (2019). Ten Years of Visualization of Business Process Models: A Systematic Literature Review. Computer Standards \& Interfaces, 66.

- Tan, W., Xu, W., Yang, F., Xu, L. and Jiang, C. (2013). A framework for service enterprise workflow simulation with multi-agents cooperation. Enterprise Information Systems, 7(4), 523-542. doi:10.1080/17517575.2012.660503

- Xuhua, H.; Spio-Kwofie, A.; BilaliibUdimal, T., and Addai, M..(2018). Entrepreneurial innovation strategies; an option for small hotels' growth in Ghana. Journal of Global Entrepreneurship Research. 30 . 